\title{
VI. The colours of the atmosphere considered with reference to a previous paper "On the colour of steam under certain circumstances."
}

James D. Forbes Esq. F. R. SS. L. \& Ed.

To cite this article: James D. Forbes Esq. F. R. SS. L. \& Ed. (1839) VI. The colours of the atmosphere considered with reference to a previous paper "On the colour of steam under certain circumstances." , Philosophical Magazine Series 3, 15:93, 25-37, DOI: 10.1080/14786443908649817

To link to this article: http://dx.doi.org/10.1080/14786443908649817

Published online: 01 Jun 2009.

Submit your article to this journal $\sqsubset$

Џ Article views: 3

View related articles $\sqsubset$ 
But it appears to me that the powers and riches of these extraordinary districts remain yet to be fully developed. They exhibit an immense number of mighty steam-engines, furnished by nature at no cost, and applicable to the production of an infinite variety of objects. In the progress of time this vast machinery of heat and force will probably become the moving central point of extensive manufacturing establishments. The steam, which has been so ingeniously applied to the concentration and evaporation of the boracic acid, will probably hereafter, instead of wasting itself in the air, be employed to move huge engines, which will be directed to the infinite variety of production which engages the attention of labouring and intelligent artisans; and thus, in the course of time, there can be little doubt, that these lagoons, which were fled from as objects of danger and terror by uninstructed man, will gather round them a large intelligent population, and become sources of prosperity to innumerable individuals through countless generations.

VI. The Colours of the Atmosphere considered with reference to a previous Paper "On the Colour of Steam under certain circumstances." By J AMES D. ForBes, Esq., F. R. SS. L. \& Ed., Professor of Natural Philosophy in the University of Edinburgh.

[Continued from vol. xiv. p. 426.]

\begin{abstract}
A TOTALLY different hypothesis from any of the preceding, as regards the blue of the sky, was about the same time started by Muncke. He asserts that this hue is, what the German writers call purely subjective, that is, an ocular deception, received by the eye on looking into vacant space*. This theory has been well discussed by Brandes, but I think he has not succeeded in explaining Muncke's fundamental experiment, which is this:- If the sky be viewed by one eye directly, and by the other through a long blackened tube, the colour in the latter case gradually seems to vanish. Now, the explanation of this optical difficulty is to be found, I conceive, in the general fact first observed by Mr. Smith $\uparrow$, and which I have verified in a great variety of cases, that when a white object is viewed at once by both eyes, one shaded, and the other powerfully illuminated, though its natural colour is undoubtedly white, it appears red to the shaded eye, and green to the other. The shaded eye in Muncke's experiment, therefore, superimposes a red impression (by the effect of contrast with
\end{abstract}

- Schweigger's Journal, xxx. 81; and article Atmosphäre in Gehler.

+ Edin. Juurnal of Science, $v, 52$. 


\section{Professor Forbes on the Colours of the Atmosphere.}

the exposed eye) on the blue which it sees, and being its complementary colour, or nearly so, it must tend to diminish the blueness, and finally to produce white.

Berzelius adopts the view which considers the air itself coloured *.

In the older writings of Sir David Brewster, we find the theory of Bouguer maintained $\uparrow$; but since he has been led to what we must consider, for a majority of cases, a refutation of the Newtonian doctrine of the colours of bodies, he was naturally induced to view with doubt the composition of the celestial blue, and especially of the colours of clouds. That the reflected and transmitted tints should be complementary, as Newton's theory assigns, is well known to be rather the exception than rule in coloured bodies generally; and a very simple prismatic analysis, which it seems difficult to misconstrue, proves that the composition of colours-the green of leaves, for instance, - - is widely different from that which the doctrine of thin plates would infert. "I have analysed too," he says, " the blue light of the sky, to which the Newtonian theory has been thought peculiarly applicable, but, instead of finding it a blue of the first order, in which the extreme red and extreme violet rays are deficient, while the rest of the spectrum was untouched, I found that it was defective in rays adjacent to some of the fixed lines of Fraunhofer, and that the absorptive action of our atmosphere widened, as it were, these lines. Hence, it is obvious, that there are elements in our atmosphere which exercise a specific action upon rays of definite refrangibility. . . . . I have obtained," he adds, " analogous results in analysing the yellow, orange, red, and purple light which is reflected from the clouds at sunset $\S . "$ Such a prismatic analysis as is here referred to, is even more satisfactory than in the case of the juices of plants, because here the very reflected light itself is examined in the state it reaches the eye. I need hardly add, that this experiment is not less conclusive against the subjective theory of Muncke, than against the theory of thin plates of water of Newton and his followers.

Forster, in his treatise on Atmospheric Phænomena, maintains the doctrines of Melvill respecting the colour of clouds. "We observe," he says, "that clouds of the same variety, having the same local or angular position with respect to the

* Lehrbuch der Chemie, Wöhler's edit. 1825, i. 346.

+ Edin. Encyclopadia, art. Optics, p. 620. Compare articles Atmosphere and Cyanometer.

$\mp$ Life of Newton, p. 78. 1831. Ed. Trans, xii. 538.

ई Ed. Trans. xii. 544. Compare Encyc. Brit. new Edition, art. Optics, p. 510. 
sun, sometimes appear richly coloured, and at other times scarcely coloured at all,-a circumstance which renders it questionable whether the colour is from the cloud itself, or whether the cloud only reflects the light which is coloured by refraction in passing through the haze of the atmosphere in the evening. The former is, however, probably the case; for different clouds, in nearly the same angular position with respect to the sun, show different colours at the same time*."

I must quote myself as having formerly adopted the theory of Bouguer, with regard at least to the celestial blue. In one of a series of papers on the Bay of Naples, published about ten years ago, I noticed the occurrence of a strictly purple tinge (the poetic lumen purpureum), in a perfectly clear sky, which I attributed to a part of the violet rays, mixed with the blue, finding their way to the eye. There is no question (notwithstanding the authority of Eustace + ), that Virgil's epithet was founded on the accurate observation of Nature. The fact has also been observed by Humboldt and by Leslieł. We now come to the theory of M. Leopold Nobili of Reggio, and which, after what has been stated, may be very briefly expounded. In quoting M. Nobili's speculations on this subject as new to me, I must observe, that they are contained in a memoir $\|$ on a certain uniform scale of colours, for the use of artists, produced by the elegant method of depositing thin layers of transparent substances on metallic surfaces, by precipitation from solutions by means of galvanic decomposition. This beautiful art of forming what Nobili calls his "Apparences Electro-chimiques," was first pointed out to me, as well as the papers describing it, by Professor Necker of Geneva, as far back as the winter 1831-2, when some members of the Society may recollect that I exhibited in this room specimens of Nobili's chromatic scale, prepared by myself $\S$.

\footnotetext{
* Researches about Atmospheric Phænomena, 3rd edit., 1823,p. 86. 'The continuation of the passage will be quoted further on.

+ "In the splendour of a Neapolitan firmament, we may seek in vain for that purple light so delightful to our boyish fancy."-Tour in Italy.

$\ddagger$ Encyclopædia Britannica, art. Meteorology.

If Bibliothèque Universelle (1830), tom. xliv. p. 337.- Translated in Taylor's Scientific Memoirs, vol. i.

$\oint \mathrm{It}$ is a curious circumstance, which $\mathrm{I}$ have never heard remarked, that Dr. Priestley in a great measure anticipated the experiment of Nobili; for, by successive electric discharges on the surface of many kinds of metal, he produced rings identical with those of Newton.--Priestley, Phil. Thans. 1778. These colours were no doubt produced by the heat developed in the same way as those mentioned in one part of Nobili's poper. The explanation of these colours, by supposing with the philosopher of Reggio (if I understand him aright), that they are produced by thin plates of adhering oxygen gas, is too evidently founded in error to require any notice.
} 


\section{Professor Forbes on the Colours of the Atmosphere.}

From an attentive comparison of the beautiful series of tints, identical with those of thin plates, so produced, Nobili endeavours to assign empirically, as Newton had done, the orders to which the colours of Nature belong; only, instead of cautiously proposing them as guesses, like his illustrious predecessor, he assigns them, with a degree of confidence but ill sustained by the now almost untenable character of Newton's theory of the colour of bodies. Many of the remarks are very ingenious, but whenever he contradicts Newton, he seems, I think, to fall into evident inaccuracy. The general question is one with which we have now nothing to do, and therefore I confine myself only to the statements which concern the present subject. Because he has banished the blue of the first order, as having no existence*, he is forced to assign to the blue of a clear sky the character of the second order; whilst he attributes the tints of flocculent clouds, partially illuminated by the sun or moon, to the first order; in other words, he supposes the vesicular vapour of which he speaks, to have double the thickness in an azure sky, than in the midst of a fog, whilst Newton expressly assigns the blue of the first order to the air, because "it ought to be the colour of the finest and most transparent skies in which vapours are not arrived at that grossness requisite to reflect other colours, as we find it is by experience." This is only one of the various contradictions into which the artist-like view of matching colours by external resemblances, and assuming a common origin, has led the ingenious author. The application of the colours reflected from vapours to measure the thickness of the vesicles $\uparrow$ was, we have seen, completely anticipated by Kratzenstein, and the generality of the application disproved by Melvill half a century ago, when he speaks of the theory of the "gaudy colours" of the ciouds arising, "like those of the soap bubble, from the particular size of their parts."

I have perused Nobili's Memoir with a most anxious wish

- Nobili quotes Amici's authority in confirmation of this novel assertion, and also for the alleged absence of green in the second order of colours. I think I can speak with much confidence as to the existence of blue of the first order in the depolarized tints of mica plates: but the attempt to show (Bibl. Univ. xliv. p. 343 and 344, note), that there ought to be no blue, and that the first colour of Newton's scale should be white, seems to me a failure, arising from a degree of misconception of first principles which it is difficult to admit.

+ In the translation of the paper in Taylor's Scientific Memoirs, i. 99, by an oversight, the maximum thickness of the cloudy vesicles is stated at the ten-millionth of an inch, instead of ten millionths of an inch, or a hundred times greater, as in the original. There is even a slight mistake in the latter; the tint he describes corresponding to plates of water, not of air, would require a thickness of seven millionths. 
to arrive at his true meaning, disembarrassed of the somewhat poetical vagueness of his own expressions, and the serious mistakes of his translator; and I believe his view to be this : - There are both transmitted and reflected tints in the sky. The transmitted ones are complementary to the blue of the sky, and therefore, according to Nobili, of the second order, whilst all the fiery tints which particularly characterize sunset as contrasted with the dawn, are colours of the first order reflected from the vesicular vapours of clouds.

An ingenious paper by Count Xavier de Maistre on the colour of air and water, appeared in the Bibliotheqque Universelle for November 1832 *. With regard to the atmosphere, the author's theory is so far similar to that of Delaval, that its colour is to be ascribed to the peculiar state of the particles of water contained in it acting on the principle of opalescence, the reflected light being blue and the transmitted orange. He thence refers to the colours of sunset, and adds, - " But it often happens that the colours are not observed, and the sun sets without producing them. It is not, therefore, to the pure air alone that we must attribute the opaline property of the atmosphere, but to the mixture of air and vapour in a particular state, which produces an effect analogous to that of the powder of calcined bones in opaline glass. Neither is it the quantity of water which the air contains that occasions these colours, for when it is very humid, it is more transparent than' it is in an opposite state, the distant mountains then appearing more distinct, - a well-known prognostic of rain, and the sun then sets without producing colours; in the fogs and vapours of the morning, the light of the sun is white, but the red colour of the clouds at sunset is generally regarded as the forerunner of a fine day, because these colours are a proof of the dryness of the air, which then contains nothing more than the particular disseminated vapours to which it owes its opaline property." In this interesting passage we have, I am persuaded, all that is known of the cause of atmospheric colours, with the single want of the link which shall show that the watery vapour is sometimes capable of absorbing all but red rays, and sometimes not $\dagger$.

* Translated in the Edin. New Phil. Journal, vol. xv.

$\uparrow$ Count Maistre explains the colour of the water by similar reasoning. He considers it blue for reflected, and yellowish-orange for transmitted light, and the green colour of the sea and some lakes he attributes to diffused particles which reflect a portion of the transmitted tint, and ningle with the blue. This is well confirmed by Davy's Observations, (Salmonia, 3rd edit. p. 317). Arago has very ingeniously applied the same reasoning to the ocean, showing that when calm it must be blue, but when ruffled, the waves acting the part of prisms, refract to the eye some of the transmitted light 


\section{Professor Forbes on the Colours of the Atmosphere.}

The late Mr. Harvey of Plymouth, gives a minute analysis of the colours of the clouds*, which he considers only explicable on the theory of absorption, which office he assigns to the particles of the clouds themselves, though he admits that these often transmit pure white light. $\mathrm{He}$ is even ready to believe that the sun has sometimes been observed blue or green, an observation which I think M. Arago has rightly considered as an optical deception arising from the contrasted colour of an intensely red sky, such as that which occurred in many parts of the world on the occasion of the dry fog of 1831 t.

Brandes's theory of the evening red is especially applicable to the rich purple hue thrown over Mont Blanc and the higher Alps $\ddagger$ after the sun has set to the plains, and that kind of redness is usually observed in cloudless skies, not like the gorgeous colouring of our northern sunsets, to which I particularly referred in my former paper. In a communication read to the British Association in 1837, M. De la Rive accounts ingeniuusly for a repetition of this phænomenon which is sometimes observed 10 or 15 minutes after the first disappeared. This he plausibly attributes to a total reflection undergone by the rays of light in the rarer regions of the atmosphere when in a state of great humidity and transparency $\|$. Probably upon the principle of multiplied reflections, the cases of preternaturally protracted twilights may be explained, such as those recorded by Kämtz§.

It is now time that we endeavour to sum up briefly the evidence we have collected.

If we exclude the theory of Leonardo da Vinci and Göthe, attributing the colour of the sky to a mixture of light and shade; and that of Muncke, which would make it a mere optical deception, we shall find the chief principles which have been maintained, reduced to three.

(1.) That the colour of the sky is that reflected by pure air, and that all the tints it displays are modifications of the re-

from the interior, and it then appears green (Comptes Rendus, 23d July 1838.). Most authors have admitted the intrinsically blue or green colour of pure water, as Newton (Optics, b. i., part ii., prop. x.), Mariotte (already quoted), and Euler: Humbolrlt seems doubtful (Voyage, 8vo, ii. 133.).

* Encyc. Metropolitana, art. Meteorology, p. 163, \&c.

+ Annuaire 1832, p. 248. Whilst this Paper is passing through the press, I have seen a notice by M. Babinet (Comptes Rendus, 25th Feb. 1839), on the subject of the blue colour of the sun, which he considers as real, and endeavours to explain by the theory of mixed plates. [See on this subject the Miscellaneous articles in the present Number.-EDIT.]

+ Germ. "Glühen der Alpen."

II Seventh Report of British Association. Transactions of Sections, p. 10.

of Lehrbuch der Meteorologie, iii. 58. 
flected and transmitted light. This is more or less completely the opinion of Mariotte, Bonguer, Euler, Leslie, and Brandes.

(2.) 'That the colours of the sky are explicable by floating vapours acting as thin plates do in reflecting and transmitting complementary colours. This was Newton's theory, which has been adopted in whole or in part by many later writers, and especially by Nobili.

(3.) On the principle of opalescence and of specific absorp. tion depending on the nature and unknown constitution of floating particles. To this theory in its various stages; we find Fabri, Melvill, De]aval, Count Maistre, and Sir D. Brewster attached.

These different views are so easily blended, and have often been so far misunderstood even by their supporters, that it is impossible to draw any definite line between them. I will notice a few of the leading points of difficulty which present themselves to some of these opinions, and tend to restrict the field of inquiry.

1. The azure of the sky cannot, I think, with any probability, be referred to the existence of those vesicular vapours which are supposed to act so important a part in the mechanism of clouds. We have no evidence direct or indirect of their existence, whenever the hygrometer is not affected, nor indeed where it does not indicate absolute dampness. 'The atmosphere we know to be pre-eminently transparent when Joaded with uncondensed vapour. That vapour may be colourless, or it may not; the presumption is, I think, that it has no colour, since the blue of heaven is always most fully developed when the dryness of the air is intense; and that even at heights which render it in the last degree improbable that any condensed vapour should exist at heights still greater. We are as ignorant of the constitution of the parts of pure vapour, as we are of the parts of pure air: vesicles are water, not vapour; - to speak of films capable of reflecting definite colours when no water exists in the air, or the hygrometer does not indicate absolute dampness, is to speak (as Berkeley said of Fluxions) of the ghosts of departed quantities.

2. Admitting that the blueness of the reflected light of the sky is an inherent quality, of which we can give no account, we must next say that it is running too fast to a solution to admit with Brandes that the red of evening is solely caused by the colour of the air being complementary to its reflected tint. His explanation of the variable redness of sunset, owing to the variable opacity of white vapours allowing the 
redness to be more or less distinctly perceived, though ingenious, is palpably wrong. The simplest experiments prove that the redness is not merely apparent, but depends upon the admixture of the variable ingredients of the atmosphere. The proof is the Prismatic Analysis of the sun's light, and we may add, the observation of artificial lights in different states of the atmosphere, which at some times are seen in their natural condition, at others lose all their rays but the red, and finally vanish in fogs with an intense red glare.

3. If fogs and clouds modify the solar light on the principle of reflecting the rays they do not transmit, why do not such fogs and clouds appear vividly blue by reflected light, as Nollet supposed a foggy atmosphere must do to a spectator placed beyond it?

4. If the vesicles constituting the clouds give to the colourless light falling upon them the various hues of sunset, why, in the first place, do we not perceive bows of various hues, as Kratzenstein did in operating on the small scale; and how comes it that clouds, identical in structure, nay, the very same clouds, do not exhibit sunset tints at any other time of day? But the most convincing proof of any, is simply to watch the progress of the solar rays tinging a cloud successively with different hues, just as it would a lock of wool similarly placed; or as it does the snowy Alpine summits. Forster mentions an instance of detached cirrocumuli being of a fine goldenyellow, but in a single minute becoming deep red.

5. To these unanswerable difficulties the prismatic analysis of the blue and sunset tints of the sky superadds one conclusive against the theory of Newton as it at present stands. The reflected blue and transmitted red-orange are not colours of thin plates. They are derived from all parts of the spectrum by the mysterious process of transmission, which has preserved them and absorbed the rest. It is hopeless at present to inquire what is the mechanical constitution of the medium which has effected this alchemy.

One question, however, which is quite within our reach, remains to be answered. The colours of the sky cannot indeed be explained, if by explanation we mean an ultimate analysis of the mechanism producing them; but the theory of absorption is incomplete until we can show in what part of the course of the rays of light, and under what varying circumstances, the different phænomena of colour may be produced. Hassenfratz observed, that the light of the horizontal sun was deficient, when analysed by the prism, in all the violet and blue rays*. Sir D. Brewster, making a similar observation

* Kämtz, Lehrbuch, iii. 40. 
with more care, has detected a specific action of the earth's atmosphere affecting every part of the spectrum by absorbing or annihilating certain luminous rays of every colour. The analogy which he has observed to exist between the deficient lines of the atmospheric spectrum, and those of the common solar spectrum, (which Sir David supposes to have been produced in the transit of light through the sun's atmosphere), and those developed in artificial light by the absorptive action of nitrous acid gas, is truly remarkable, and has led him further to conclude, "that the same absorptive elements exist" in all those media*. Now, since it is the strata of air nearest to the earth whose effect is chiefly conspicuous in producing the tints of evening, it is to be presumed that the elements which produce this action, are within reach of chemical analysis. The air, containing as it does the constituents of nitrous acid gas, is naturally first looked to for their origin. But this supposition, even if it be true, for the atmospheric lines of the spectrum, cannot explain the extraordinary variety of absorptive action observed in hazy weather, when, as we have said, the atmosphere at a thickness of but a few miles suffers only the red rays to pass; a fact familiar to those who have attended to the subject of light-house illumination, and in consequence of which crimson signal-lights were proposed a few years ago for adoption in hazy weather by Sir John Robisont, on account of the persistence of such rays in a foggy atmosphere. The absorptive elements are clearly within our reach; can they be nitrous gas, or what are they? The experiment detailed in my last paper comes in to answer the question. Vapour has hitherto been known (to philosophers at least) under but two characters, - a colourless gaseous body, and a translucent pure white mass of particles generally called vesiculart. I have shown that it passes through a third or intermediate state, in which it is very transparent, but having a more or less intense colour graduating through the very. shades which nitrous acid gas assumes, - that is, tawny yellow, orange, deep orange-red, intense smoke-red, verging on blackness. I say that this discovery, to a great extent, supplies the gap which was wanting to make the absorption theory intelligible. It is the "mixture of air and vapour in a particular state," which Count Maistre supposed (see the passage quoted above), but could not prove to exist. The threefold condition of vapour in the sky we can now exhibit in a room;the pure elastic fluid devoid of colour, which gives even to

* Ed. Trans. xii. 530.

$\ddagger$ See Robison's Works, ii. 2 , \&c.

† Phil. Mag. 1833.

Phil. Mag. S. 3. Vol. 15. No. 93. July 1839. 


\section{Professor Forbes on the Colours of the Atmosphere.}

pure air its greatest transparency, - next, the transition state, when, still invisible in form, and almost certainly not vesicular, it transmits a steady orange glare, not the play of colour which is often seen in clouds and fogs forming a glory round a radiant body; - and lastly, the vesicular steam, such as we every day see issuing from the spout of a tea-kettle reflecting iridescent colours, just as the semi-opake clouds do which seem to float across the disk of the sun or moon. These coronæ, notwithstanding their apparent analogy to the colours of thin plates, seem rather to be due to the effect of diffraction*.

The non-appearance of the lines of the spectrum in my experiment, may be plausibly explained in the following manner, which, however, I offer merely as a conjecture. When steam of high pressure issues from an orifice, a horizontal section of the expelled column will include vapour in every stage of condensution. Its centre, up to a certain height, will be pure invisible steam; at the exterior of all, in contact with the cold air, there will manifestly be vesicular steam, and a cylindrical space between the two will contain red steam. Now it is extremely probable, that when the experiment is performed on the small scale, as I have described it, by suffering light to pass through such a compound column, and then analysing it by the prism, enough of unabsorbed rays are reflected from the highly luminous surface of the vesicular steam to prevent the fine lines from being seen if they exist. And $I$ am strongly confirmed in this conjecture by the fact, that when the rush of steam is very violent, and always when much vesicular vapour is present, the unabsorbed part of the spectrum presents a washy and impure tint (particularly mentioned in my former paper), which probably arises from a blending of the colours, produced by this cause.

In conclusion, I have only a word or two to say respecting the application of these facts to atmospheric appearances regarded as prognostics of weather. The modified hues of the sky, and of the sun and moon near the horizon, have, for so many ages, and in so many countries, been regarded as the surest indications of atmospheric changes, that we cannot doubt that it is to the variety of conditions in which vapour exists in the air, more or less nearly condensed, that these phænomena are due. Humboldt describes the colour and form of the sun's disc at setting in tropical regions, as the most infallible prognostic $t$, and elsewhere ascribes these variations "to a particular state of the vesicular vapourt."

* See Young's article Chromatics, in Encyc. Brit., and Fraunhofer in Schumacher's Astronomische Abhandlungen. Drittes Heft, 1825.

$\dagger$ Rélation Historique, 8vo, ii, 128. † New Spain (translation), ii, 326. 
Since the red steam occurs only during the critical stage of its partial condensation (and perhaps conversely during evaporation), it is evident that it must correspond to a critical state of diffused vapour of the atmosphere. The applications might be very extended; I will only advert to one, the surest, most consistent, and probably the most ancient of such prognostics. The red evening and grey morning as the signs of fine weather, are recorded in the verses of Aratus*, in the New Testament $\dagger$, and in one of our most familiar proverbs. It is wholly inexplicable on the theory of Brandes, which considers the redness as due solely to the purity of the atmosphere, since that is usually greater in the morning than the evening. According to my view it occurs thus: Soon after the maximum temperature of the day and before sunset, the surface of the ground, and likewise the strata at different heights in the atmosphere, begin to lose heat by radiation. This is the cause of the deposition of dew, and consequently in severe weather we have vast tracts of air containing moisture in that critical state which precedes condensation, and yet it may be exceedingly doubted whether any vapour properly called vesicular is necessarily formed in this process. Be that as it may, every accurate observer of nature in alpine countries will confirm me in stating, that fine weather is almost invariably accompanied by the formation of dew on exposed surfaces, and by the progressive depression of the moister strata, until at length visible fogs are formed in the bottom of the valleys, and especially over waterf. This is the surest sign of a following fine day in mountainous regions. Now Saussure in his ascent of Mont Blanc, "observed that the evening vapour which tempered the sun's brightness, and half concealed the immense space he had below him, formed the finest purple belt, éncircling all the western horizon, and as the vapour descended and became more dense, became narrower and of a deeper colour, and at last of a blood-red ||." Now this phænomenon corresponds, I imagine, precisely to the development of colour which $I$ have remarked in vapour in the act of being condensed, and De la Rive's remark, that the nocturnal illumination of Mont Blanc takes place in serene evenings, when the

* Diosemeia, 93. quoted by Kämtz.

+ Matt. xvi. 2, 3.

‡ For the reason why over water, see Davy's Paper, Phil. Trans. 1819.

II. Quoted by Harvey in Ency. Metrop. Meteorology, p. *166. The cause of the purple light mentioned here, probably arises fron a nixture of the reflected blue of the pure sky (which is always present when purple is seen) with the yellow-orange, which condensing vapour first transmits. I do not think it at all necessary to affirm, however, that pure air has no transmitted colour of its own. 


\section{Professor Forbes on the Colours of the Atmosphere.}

air is highly charged with moisture, is to the same purpose. But a remark of Mr. Forster, in his "Researches about Atmospheric Phænomena*," is even more pointed, and is valuable, because his work is pre-eminently descriptive, rather than theoretical. "Sometines the tints in the twilight haze come on so suddenly and are so circumscribed, as to induce a belief that very sudden and partial changes take place in the atmosphere at eventide; which may perhaps be somehow connected roith the formation of dew." "He then records an observation made 2nd November 1822. "Being about four o'clock in the evening, near Croydon in Surrey, I observed a very beautiful western sky, caused by the bright edge and dependent fringes of a light bed of cloud being finely gilded by the setting sun. Some detached cirrocumuli also, which formed the exterior boundaries of the aforesaid cloud, were likewise of a fine golden-yellow, and the same colour appeared in different clouds in other parts of the sky, while the scudlike remains of the nimbus floated along in the west wind below. In the course of about a quarter of an hour, the lofty gilded clouds all assumed a deep red appearance, and the change was effected so suddenly, that while looking at them, I only took my eyes off them for a minute to stop down the tobacco in a pipe that I was smoking, and when I looked up at them again, the colour was totally changed. Now, what renders the phænomenon remarkable is, that it happened just about the period of the vapour point. The descending sun had scarcely had time to make any great difference in the angle of reflection, and it seemed therefore, that some sudden change, produced by the first falling dew, was the cause of this simultaneous change of colour in all the clouds then visible." I confess it seems to me that this passage is nothing short of a demonstration of the truth of my theory of Atmospheric Colour, the more interesting, because I was unacquainted with it until after writing nearly the whole preceding part of this paper.

With regard to the morning the case is very different. In fine weather the strata near the surface of the earth alone, and in the lowest and most sheltered spots, are in a state of absolute dampness. The vapours, which, during the reversion of the process, might probably produce colour, are not elevated until the action of the sun upon the earth's surface has continued long enough to impart a sensible warmth, by which time the moment of sunrise is past, and the sun's disc has risen above the horizontal vapours. It would be easy, by a more lengthened discussion, to show, that the slowly progressive

* Third edit.p. 87. 
transition of vast masses of air through the temperature of the dew-point, can only occur in serene weather at sunset and not at-sunrise. "The inflamed appearance of the morning sky, considered indicative of foul weather, is, I have no doubt, owing to such an excess of humidity being present, that clouds are actually being formed by condensation in the upper regions, contrary to the direct tendency of the rising sun to dissipate them, which must therefore be considered as indicating a speedy precipitation of rain.

Edinburgh, 4th February, 1839.

VII. Obscrvations on an improved Construction of the Voltaic sustaining Battery. By F. W. Mullins, Esq., F.G.S. F.S.S., \& c.*

THREE years have elapsed since $I$ introduced to the public at one of the Friday-Evening Meetings at the Royal Institution, my mode of construction of the voltaic sustaining battery. "This battery was then in its simplest form, being nothing more than a coil or cylinder of copper inclosed in a thin bladder containing a solution of sulphate of copper, both being placed in an earthenware pot, holding a cylinder of amalgamated zinc inmersed in a solution of muriate of ammoniat. In this arrangement the sulphate of copper solution had communication with the internal as well as the external surface of the copper cylinder; but subsequent experiments having convinced me that there was no use, but rather an injury, in permitting access of the sulphate solution to the internal surface of the copper, I altered the arrangement so far as to close the bottom of the cylinder, and throw the rohole of the salt of copper, as it dissolved, upon a shelf at the upper part of the cylinder, through holes in its circumference on a level with the shelf into the space between the two metallic surfaces, where of course it was most needed. 'The first of these arrangements was worked for a short time after it was made public at the Adelaide Gallery of Science, the other subsequently, and both are described in the Phil. Mag. for Oct. 1836. I am thus particular in adverting to the two modes of construction adopted by myself, in consequence of ascertaining that some would-be scientific persons, with less of discretion or honesty than of puerile vanity, have since the period referred to attempted to arrogate to themselves whatever merit there might have been in the arrangement in which the sulphate solution is used internally as well as externally; and I have reason to know that batteries so arranged have been palmed upon many as superior to those which after a long

* Communicated by the Author.

$\uparrow$ See Phil. Magazine for October 1836, p. 283. 